\title{
A Comparative Evaluation of Two Commonly Used GP Solvents on Different Epoxy Resin-based Sealers: An In Vitro Study
}

\author{
Sakshi Tyagi ${ }^{1}$, Ekta Choudhary ${ }^{2}$, Ashish Choudhary ${ }^{3}$, Rajat Chauhan ${ }^{4}$
}

\begin{abstract}
Aim: This study evaluates epoxy resin-based sealers after their final set, immersed in Endosolve-R or xylene for 1-2 minutes, for its easy removal mechanically after softening.

Materials and methods: Sixty Teflon molds were grouped with 20 samples in each of the three commercially available sealers, i.e., AH 26 , $\mathrm{AH}$ Plus, and Adseal. The sealers were put in the specific molds after their manipulation as per the instructions given in the literature by the manufacturer. They were allowed to harden for 2 weeks at $37^{\circ} \mathrm{C}$ in $100 \%$ humidity. Two subgroups, A-Xylene and B-Endosolv-R, of 10 samples each, were formed from 20 set specimens based on solvents to which they were immersed for 1 and 2 minutes, respectively. The data obtained was subjected to the Mauchly's test one-way ANOVA and two-way ANOVA for analysis.

Results: It was proved that for all the sealers immersed in solvents, there was a significant reduction in the mean Vickers hardness as the time increases. There was a significant difference in the initial hardness between the mentioned sealers with AH plus showing the highest followed by $\mathrm{AH} 26$ and Adseal showing the lowest. AH Plus and Adseal sealers were softened by xylene after 2 minutes of their initial microhardness $(p<0.001)$; least effect was seen on AH 26. After 2 minutes, Endosolv- $\mathrm{R}$ softened initial microhardness of all the three sealers $(p<0.001)$.

Conclusion: It was concluded that Endosolv-R was more effective in softening the epoxy-based resin sealer than xylene, after 2 minutes of exposure.
\end{abstract}

Keywords: Endodontic solvents, Microhardness, Resin-based sealers.

International Journal of Clinical Pediatric Dentistry (2020): 10.5005/jp-journals-10005-1741

\section{INTRODUCTION}

The success rate of root canal treatment ranges from 86 to $93 \%$ and the most common cause of its failure is the microbial infections of the root canal system. ${ }^{1}$ Root canal-treated teeth can be retreated either by orthograde or retrograde retreatment. There are various reasons of endodontic failure such as left-out canals, inappropriate cleaning, under/overobturation, inefficient hermetic seal, and bacterial microflora in the root canal. ${ }^{2}$ When resin-based sealers are used, retreatment and removal of the gutta percha (GP) is not easy. Therefore, different solvents can be used along with the mechanical method to avoid complications like altering of the original canal shape, canal straightening, or perforations. ${ }^{3-5}$ This study was designed to evaluate two GP solvents on three commercially procured epoxy resin-based sealers.

\section{Materials and Methods}

\section{Root Canal Sealers Used: Epoxy Resin Based}

- $\mathrm{AH} 26$ (group I)

- AH Plus (group II)

- Adseal (group III)

\section{Solvents Used}

- Xylene (subgroup A)

- Endosolv-R (subgroup B) \begin{tabular}{l}
\hline 1,2Department of Conservative Dentistry and Endodontics, School of \\
Dental Sciences, Sharda University, Greater Noida, Uttar Pradesh, India \\
${ }^{3}$ Department of Prosthodontics and Crown and Bridge, School of \\
Dental Sciences, Sharda University, Greater Noida, Uttar Pradesh, India \\
${ }^{4}$ Department of Orthodontics and Dentofacial Orthopedics, School of \\
Dental Sciences, Sharda University, Greater Noida, Uttar Pradesh, India \\
Corresponding Author: Sakshi Tyagi, Department of Conservative \\
Dentistry and Endodontics, School of Dental Sciences, Sharda \\
University, Greater Noida,Uttar Pradesh, India, Phone:+917982278923, \\
e-mail: drsakshi5tyagi@gmail.com
\end{tabular}

How to cite this article: Tyagi S, Choudhary E, Choudhary A, et al. A Comparative Evaluation of Two Commonly Used GP Solvents on Different Epoxy Resin-based Sealers: An In Vitro Study. Int J Clin Pediatr Dent 2020;13(1):35-37.

Source of support: Nil

Conflict of interest: None

\section{Specimen Preparation}

Sixty disks of Teflon measuring $12 \times 2 \mathrm{~mm}$ in diameter and height with a well of $1.5 \times 6.0 \mathrm{~mm}$ in depth and diameter were fabricated. The molds were divided into three groups of 20 samples each. The sealers were put in the specific molds after their manipulation as per the instructions given in the literature by the manufacturer. They were allowed to harden for 14 days at $37^{\circ} \mathrm{C}$ in $100 \%$ humidity. Two subgroups, $A$ (Xylene) and B (Endosolv-R) of 10 samples each, were

(0) The Author(s). 2020 Open Access This article is distributed under the terms of the Creative Commons Attribution 4.0 International License (https://creativecommons. org/licenses/by-nc/4.0/), which permits unrestricted use, distribution, and non-commercial reproduction in any medium, provided you give appropriate credit to the original author(s) and the source, provide a link to the Creative Commons license, and indicate if changes were made. The Creative Commons Public Domain Dedication waiver (http://creativecommons.org/publicdomain/zero/1.0/) applies to the data made available in this article, unless otherwise stated. 
formed from 20 set specimens based on solvents to which they were immersed in, for 1 and 2 minutes, respectively.

\section{Measuring the Softening of the Sealer Surface}

The Mitutoyo microhardness testing machine with an indenter was used to calculate the Vickers microhardness (HV) of all the specimens. The specimens were then subjected for 10 seconds to a load of $10 \mathrm{~g}$ at three different, predetermined points by the indenter and were measured under the microscope with 100 times magnification. The mean was calculated for the samples.

Specimens were immersed in the mentioned solvents for 60 seconds. They were air-dried after retrieval from the solvent and the microhardness was reassessed. Each specimen was again immersed in corresponding solvents for another 1 minute.

A total of 10 specimens from every group were assessed for microhardness after 1 and 2 minutes in solvent immersion. Data were collected and tabulated to obtain mean and standard deviation.

The two-way analysis of variance (ANOVA) was performed to assess the mean hardness across the groups. Data were also subjected to one-way ANOVA, followed by pairwise comparison using the Tuckey's post hoc analysis.

\section{Results}

With time, hardness reduced considerably for all the sealers and solvents. Tables 1 and 2 show mean and standard deviation of Vickers microhardness of root canal sealers immersed in the solvents for 1 and 2 minutes.

Highest reduction in the mean hardness (HV) was seen in the AH Plus sealer as compared to the other two. It was more evident for Endosolv-R in case of AH Plus. Among the three groups, subgroups $A$ and $B$ showed considerable difference in the mean hardness after 1 and 2 minutes but the result was constant after 1 minute in subgroup B. After 2 minutes, the mean hardness (HV) of group I was considerably different than groups II and III, while the means of groups II and III showed no variation.

After 60 seconds, Endosolv-R was most favorable in dissolving Adseal then $\mathrm{AH} 26$ and $\mathrm{AH}$ plus as compared to xylene that was most favorable in dissolving AH Plus then Adseal and minimum in $\mathrm{AH} 26$. After 2 minutes, Endosolv- $\mathrm{R}$ was most favorable in dissolving $\mathrm{AH}$ plus followed by Adseal and $\mathrm{AH} 26$ as compared to xylene that was

Table 1: Mean and standard deviation of Vickers microhardness after exposure to subgroup A (xylene) of all three sealers

\begin{tabular}{llrl}
\hline Time & Group I & \multicolumn{1}{l}{ Group II } & \multicolumn{1}{l}{ Group III } \\
\hline Initial hardness & $145.71 \pm 7.83$ & $155.31 \pm 5.83$ & $120.54 \pm 8.33$ \\
Hardness after & $134.21 \pm 8.0$ & $20.80 \pm 1.52$ & $41.75 \pm 5.63$ \\
1 minute & & & \\
$\begin{array}{l}\text { Hardness after } \\
2 \text { minutes }\end{array}$ & $130.04 \pm 8.20$ & $17.20 \pm 0.54$ & $31.52 \pm 4.99$ \\
\hline
\end{tabular}

Table 2: Mean and standard deviation of Vickers microhardness after exposure to subgroup B (Endosolv-R) of all the three sealers

\begin{tabular}{lrrr}
\hline Time & \multicolumn{1}{c}{ Group I } & \multicolumn{1}{l}{ Group II } & \multicolumn{1}{l}{ Group III } \\
\hline Initial hardness & $137.61 \pm 7.67$ & $156.92 \pm 6.89$ & $120.90 \pm 5.65$ \\
Hardness after & $50.33 \pm 3.84$ & $61.24 \pm 5.87$ & $33.53 \pm 4.81$ \\
$\begin{array}{l}1 \text { minute } \\
\text { Hardness after }\end{array}$ & $15.69 \pm 1.67$ & $7.23 \pm 0.43$ & $9.80 \pm 1.20$ \\
2 minutes & & & \\
\hline
\end{tabular}

most effective against AH Plus (79.1\%) followed by Adseal (65.1\%) and least effective against $\mathrm{AH} 26$ (7.6\%).

\section{Discussion}

In any retreatment case, complete removal of the sealer and the gutta percha is very crucial, in order to facilitate entry for the antimicrobial agent, disinfectant, and medicament in the canal and further, to ensure its success. ${ }^{6,7}$

Whenever resin-based sealers are used, retreatment and removal of the gutta percha becomes difficult. Therefore, different solvents can be used along with the mechanical method, to avoid complications like altering of the original canal shape, canal straightening, or perforations.

Xylene, chloroform, Pandine needle oil, eucalyptol oil, turpentine oil, etc., are commonly used solvents in the nonsurgical retreatment cases for easy removal of root canal fillings.

About $60-70 \%$ of the gutta percha can be easily removed within 2-3 minutes but some firmly adhered remnants of the sealer and the gutta percha that remained attached to the canal dentin walls are difficult to remove; therefore, along with solvents various mechanical methods have been well documented like using files, gates glidden, heated pluggers, ultrasonic, etc., for complete removal of root canal fillings. ${ }^{5,8,9}$ Also "wicking action" by solvents as suggested by Ruddle is most effective in removal of the gutta percha in cases of retreatment. ${ }^{10}$

In this study, resin-based sealers have been used as they firmly adhere to dentin walls and are difficult to remove as compared to nonresin-based sealers. ${ }^{11}$ Various authors have suggested that these resin-based sealers are biocompatible, radiopaque, and firmly adhere to both gutta percha and dentinal walls; therefore, they are difficult to remove in retreatment cases. ${ }^{12-14}$

The study compared three sealers after being immersed in two different solvents (Endosolv-R and xylene) for 1 and 2 minutes. It was found that Endosolv- $R$ was the most effective softener for all the three sealers in less time. ${ }^{15}$

Due to hydrophobic property of Endosolv-R and xylene, they have the capacity to break through the $3 D$ lattice structure of epoxy resin-based sealers formed after the chemical reaction. ${ }^{15}$ A combined use of Endosolv-R along with rotary files for removal of the gutta percha from apical third in less time has been well reported by various authors. ${ }^{6,16}$ Evident reduction in microhardness of the enamel and the dentin along with reduction in the binding force of resin-based endodontic sealers with use of xylene have also been noted. ${ }^{17,18}$

The U.S. Food and Drug Administration has barred chloroform for its carcinogenicity and cytotoxicity. ${ }^{17,19}$ An endodontic solvent like orange oil is more popular because of its safe and biocompatible nature, even though few authors have suggested orange oil to be less effective than chloroform and xylene. ${ }^{20}$ Xylene is mainly composed of chlorinated hydrocarbon that has the capability to dissolve the gutta percha and the sealer; when used along with the mechanical methods, it can facilitate easy removal of filling materials. ${ }^{16}$ Whereas, Endosolv-R that contains formamide (66.5 $\mathrm{g}$ ) and phenyl ethylic alcohol $(33.5 \mathrm{~g})$ is more effective for removal of the resin-based sealer. ${ }^{21}$

The Occupational Safety and Health Administration stated the adverse effect of xylene, which includes hypersensitivity of the mucous membrane and the eye, when ingested causes gastrointestinal discomfort, when inhaled causes air spaces hemorrhages, chemical pneumonitis, if extruded periapically 
causes cytotoxic reaction. ${ }^{22}$ Chutich et al. have recommended that the quantity of xylene that leaches out of the apical foramen is way less than the permissible dose. ${ }^{23}$ Biological acceptability of Endosolv- $\mathrm{R}$ is questionable as it is known to have fetotoxic properties. $^{24}$

\section{Conclusion}

It was concluded that Endosolv- $R$ was more effective for softening the epoxy-based resin sealer than xylene, after 2 minutes of exposure. Further studies are required with long-term trials and varying parameters simulating the clinical conditions.

\section{References}

1. Rubino GA, Akisue E, Nunes BG, et al. Solvency capacity of guttapercha and resilon using chloroform, eucalyptol, orange oil or xylene. J Health Sci Inst 2012;30:22-25.

2. Hülsmann M, Bluhm V. Efficacy, cleaning ability and safety of different rotary $\mathrm{NiTi}$ instruments in root canal retreatment. Int Endod J 2004;37(7):468-476. DOI: 10.1111/j.1365-2591.2004.00823.x.

3. Kfir A, Tsesis I, Yakirevich E, et al. The efficacy of five techniques for removing root filling material: microscopic versus radiographic evaluation. Int Endod J 2012;45(1):35-41. DOI: 10.1111/j.13652591.2011.01944.x.

4. Punitha PG, Shashikala K. Evaluation of adaptation of resin based sealers Epiphany, AH plus and AH 26 to the root canal dentin by scanning electron microscope. Indian J Stomatol 2011;2:207-211.

5. Duncan HF, Chong BS. Removal of root filling materials. Endod Topic 2008;19(1):33-57. DOI: 10.1016/j.bbapap.2007.08.017.

6. Ramzi H, Shokouhinejad N, Saghiri MA, et al. Efficacy of three different methods in the retreatment of root canals filled with Resilon/ Epiphany SE. Iran Endod J 2010;5(4):161-166.

7. Grossman. Grossman's Endodontic Practice. 12th ed., New Delhi: Wolters Kluwer; 2010. pp. 278-307.

8. Shin SJ, Lee Y, Park JW. Evaluation of retrievability using a new soft resin based root canal filling material. J Korean AcadConserv Dent 2006;31(4):323-329. DOI: 10.5395/JKACD.2006.31.4.323.

9. Taşdemir T, Yildirim T, CelikD. Comparative study of removal of current endodontic fillings. J Endod 2008;34(3):326-329. DOI: 10.1016/j. joen.2007.12.022.

10. Ruddle CJ, (2001). Nonsurgical retreatment of endodontic failures: treatment concepts and considerations. Endodontic therapy. Available from http://www.endoruddle.com/tc2pdfs/49/ NSRCTOverview_Jun2004.pdf [Accessed June 2017].

11. Bodrumlu E, Uzun O, Topuz O, et al. Efficacy of three techniques in removing root canal filling material. J Can Dent Assoc 2008;74(8):721.

12. Lee KW, Williams MC, Camps JJ, et al. Adhesion of endodontic sealer to dentin and gutta-percha. J Endod 2002;28(10):684-688. DOI: 10.1097/00004770-200210000-00002.

13. Mamootil K, Messer HH. Penetration of dentinal tubules by endodontic sealer cements in extracted teeth and in vivo. Int Endod J 2007;40(11):873-881. DOI: 10.1111/j.1365-2591.2007.01307.x.

14. Kim CK, Ryu HW, Chang HS, et al. Evaluation of the radiopacity and cytotoxicity of resinous root canal sealers. J Korean Acad Conserv Dent 2007;32(5):419-425. DOI: 10.5395/JKACD.2007.32.5.419.

15. Kfir A, Rosenberg E, Tamse A, et al. Can epoxy resin-based endodontic sealers be softened within 1-2 min? An in vitro study with chloroform and xylene. Endod Pract Today 2012;6:189-194.

16. Vranas RN, Hartwell GR, Moon PC. The effect of endodontic solutions on resorcinol-formalin paste. J Endod 2003;29(1):69-72. DOI: 10.1097/00004770-200301000-00019.

17. Shokouhinejad N, Sabeti MA, Hasheminasab M, et al. Push-out bond strength of resilon/epiphany self-etch to intraradicular dentin after retreatment: a preliminary study. J Endod 2010;36(3):493-496. DOI: 10.1016/j.joen.2009.11.009.

18. Jacob S, Lakshmi Narayann L. Effect of chloroform, xylene and halothane on enamel and dentin micro-hardness of human teeth. Endodontol 2000;12:3-6.

19. Hansen MG. Relative efficiency of solvents used in endodontics. $J$ Endod 1998;24(1):38-40. DOI: 10.1016/S0099-2399(98)80211-2.

20. Mushtaq M, Masoodi A, Farooq R, et al. The dissolving ability of different organic solvents on three different root canal sealers: in vitro study. Iran Endod J 2012;7(4):198-202.

21. Gambrel MG, Hartwell GR, Moon PC, et al. The effect of endodontic solution on resorcinol-formalin paste in teeth. J Endod 2005;31(1):2529. DOI: $10.1097 / 01$. don.0000147783.02453.82.

22. U.S. Department of Labor (1978). Occupational safety and health guideline for Xylene. [online].CDC website. Available from https:// www.cdc.gov/niosh/docs/81-123/pdfs/0668.pdf [Accessed June 2017].

23. Chutich MJ, Kaminski EJ, Miller DA, et al. Risk assessment of the toxicity of solvents of gutta-percha used in endodontic retreatment. J Endod 1998;24(4):213-216. DOI: 10.1016/S0099-2399(98)80098-8.

24. Spécialités Septodont: Endosolv. Product for removing canal fillings. [online]Available from: http://www.septodont.ca/sites/default/files/ Endosol\%20E\%20R.pdf. 